\title{
Vasculite necrosante na glomerulonefrite difusa aguda pós-infecciosa
}

\section{Necrotizing vasculitis in acute postinfectious glomerulonephritis}

Márcia C. Riyuso'; Maria Fernanda C. Carvalho²; Amélia A. T. Trindade3; Luciana B. Mendonça'; Fabiano P. Saggioro ${ }^{4}$; Rosa M. Viero ${ }^{5}$

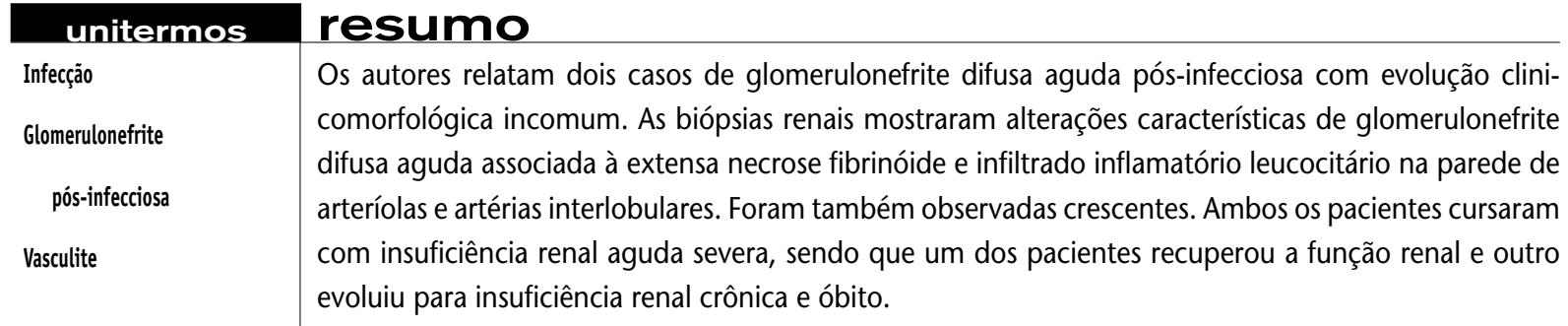

The authors report two cases of postinfectious acute diffuse glomerulonephritis with uncommon followup. The kidney biopsies showed characteristic features of postinfectious acute glomerulonephritis with extensive fibrinoid necrosis and polymorphonuclear inflammatory infiltrate in the walls of arterioles and interlobular arteries. Celular crescents were also seen. The patients follow with severe acute renal failure; one patient improved the renal function and one progressed to chronic renal failure and died.

\section{key words}

Infection

Postinfectious

glomerulonephritis

Vasculitis

\section{Introdução}

A vasculite aguda necrosante de pequenos vasos é de ocorrência rara na glomerulonefrite difusa aguda pós-infecciosa (GNDA). Há na literatura 13 casos relatados de GNDA pós-estreptocócica com vasculite necrosante, oito crianças e cinco adultos jovens, que cursaram com quadro nefrítico agudo, proteinúria e insuficiência renal ${ }^{(1-4,7)}$.
As lesões vasculares podem ser localizadas ou disseminadas em vários órgãos, e não têm indicado pior prognóstico para os pacientes ${ }^{(1,2,4)}$. Caracterizam-se por necrose fibrinóide da parede vascular decorrente de reação de hipersensibilidade por imunocomplexos circulantes após infecção estreptocócica ${ }^{(2,7)}$.

Estamos relatando dois casos: uma criança e um adulto com GNDA pós-infecciosa que cursaram com

1. Professora-ass

2. Professora-assistente-doutora da disciplina de Nefrologia do Departamento de Clínica Médica da FMB/Unesp.

3. Médica; disciplina de Nefrologia do Departamento de Clínica Médica da FMB/Unesp.

4. Residente em Patologia; Departamento de Patologia da FMB/Unesp.

5. Professora-assistente-doutora do Departamento de Patologia da FMB/Unesp. 
formação de crescentes e arterite necrosante. A criança evoluiu com melhora da função renal sendo acompanhada ambulatorialmente e o outro paciente cursou com insuficiência renal crônica e óbito.

\section{Relato dos casos}

\section{CASO 1}

E. H. S, sexo masculino, branco, 11 anos, procedente de Palmital (SP). Foi internado em hospital de sua cidade, queixando-se, havia dois dias, de diminuição do apetite, edema de face, diarréia, vômitos e urina escura. Na internação foi constatada hipertensão arterial com PA $=220 / 120 \mathrm{mmHg}$ e temperatura de $38^{\circ} \mathrm{C}$. Após uma semana iniciou quadro de oligúria, sendo encaminhado para UTI em hospital de Ourinhos (SP). Evoluiu com anúria, necessitando de diálise peritoneal e, após quatro semanas do início da doença, mantinha-se em anúria, com episódios de vômitos e pressão arterial controlada sem medicação, sendo encaminhado ao nosso serviço para investigação diagnóstica.

Ao exame físico apresentava-se em bom estado geral, com edema de $1 / 4+$ em membros inferiores, peso $=78,4 \mathrm{~kg}$, estatura $=157 \mathrm{~cm}, P A=100 / 70 \mathrm{mmHg}$, $\mathrm{Fc}=76 \mathrm{bat} / \mathrm{min}, \mathrm{FR}=26 \mathrm{mov} / \mathrm{min}$. Estava com cateter de Tenchkoff, sendo mantido em diálise peritoneal contínua com cicladora.

Exames laboratoriais de entrada: hemograma: $\mathrm{Ht}=28 \%, \mathrm{Hb}=9,2 \mathrm{~g} / \mathrm{dl}$; bioquímicos: proteínas totais $=8,2 \mathrm{~g} \%$, albumina $=2,9 \mathrm{~g} \%, \mathrm{Na}=138 \mathrm{mEq} / \mathrm{l}$, $\mathrm{K}=4,3 \mathrm{mEq} / \mathrm{l}, \mathrm{Ca}=8,4 \mathrm{mg} \%, \mathrm{P}=8,6 \mathrm{mg} \%, \mathrm{Mg}=1,5 \mathrm{mg} \%$, uréia $=172 \mathrm{mg} \%$, creatinina $=18,3 \mathrm{mg} \%, F A N=$ negativo, Anca $=$ negativo. Ultra-som renal: normal para a idade, com hiperecogenicidade.

Devido à presença de vômitos, foi feita endoscopia digestiva no segundo dia de internação, evidenciando-se hérnia de hiato e duodenite com investigação negativa para Helicobacter pylori. Recebeu tratamento com domperidona e omeprazol com desaparecimento dos vômitos.

Submetido à biópsia renal, no quinto dia de internação, que mostrou glomerulonefrite proliferativa difusa endocapilar exsudativa com $17 \%$ de crescentes celulares (Figura 1). Mostrava ainda extensa necrose fibrinóide e infiltrado inflamatório neutrofílico na parede de arteríolas (Figura 2). Observamos ainda nefrite tubulointersticial linfomononuclear e necrose tubular aguda. A imunofluorescência demonstrou depósitos granulares difusos de $\mathrm{C}_{3}$ em alças capilares, mesângio e em parede de arteríolas. $\stackrel{\AA}{A}$

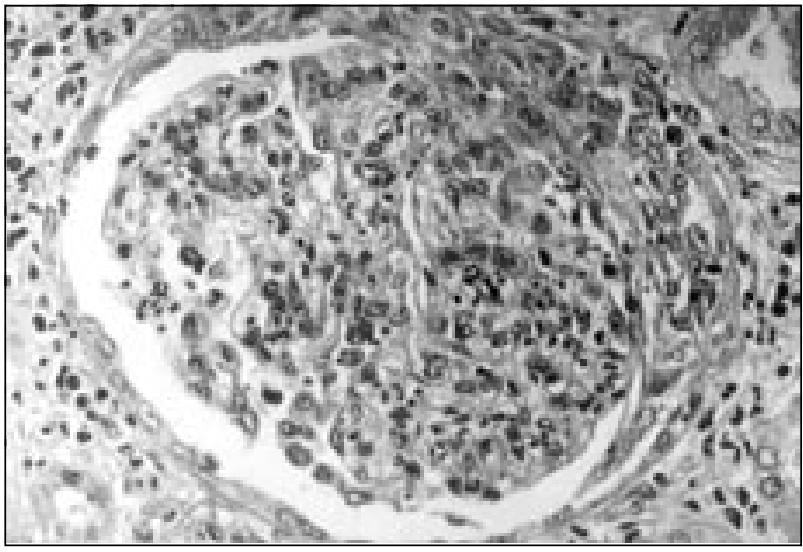

Figura 1 - Glomerulonefrite proliferativa exsudativa com crescente celular (HE - 400X)

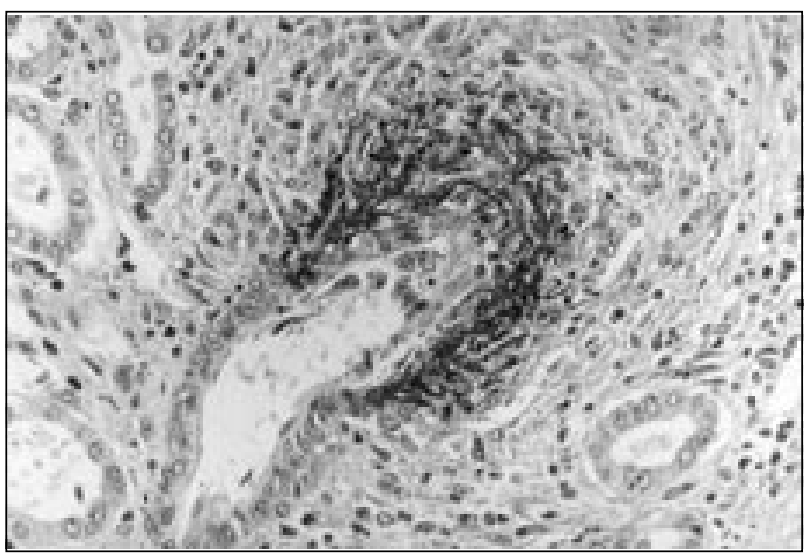

Figura 2 - Arterite aguda necrosante (Massom - 660X)

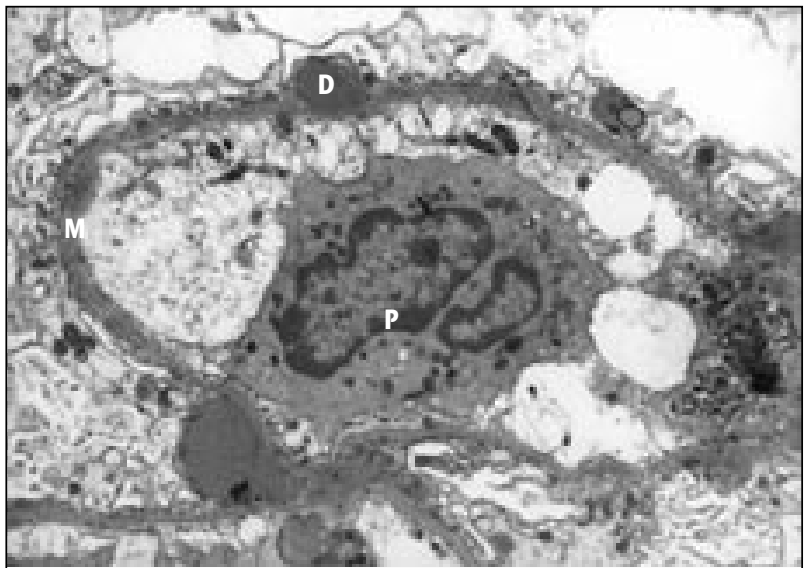

Figura 3 - Glomérulo com depósitos subepiteliais e polimorfonuclear na luz capilar ( $P=$ polimorfonuclear; $D=$ depósitos; $M=$ membrana basal glomerular); ME - 10.000X

microscopia eletrônica observamos depósitos eletrodensos mesangiais, subendoteliais e subepiteliais (Figura 3).

No $14^{\circ}$ dia de internação, o paciente iniciou tratamento com dois ciclos de pulsoterapia, recebendo três doses de $1 \mathrm{~g}$ de metilprednisolona intravenosa/ciclo, intercaladas com $40 \mathrm{mg} /$ dia de prednisona oral. Posteriormente foi mantido com prednisona oral na dose de $40 \mathrm{mg} / \mathrm{dia}$ com regressão de $10 \mathrm{mg}$ semanalmente. No $20^{\circ}$ dia de inter- 
nação apresentou quadro de hipertensão arterial, sendo tratado com propanolol, posteriormente associado ao minoxidil. No $26^{\circ}$ dia de internação, três dias após a sexta dose de metilprednisolona, o paciente aumentou a diurese de $10 \mathrm{ml} /$ dia para $120 \mathrm{ml} /$ dia e apresentava hematúria macroscópica.

Como intercorrências apresentou quadro febril com cultura de urina positiva para fungos. As culturas do líquido peritoneal e sangue foram negativas. Foi tratado com anfotericina B por 21 dias e recebeu alta hospitalar após 44 dias de internação, com $p=79 \mathrm{~kg}$, sem edemas e vômitos, diurese de $900 \mathrm{ml}$ e pressão arterial controlada com propanolol e minoxidil.

Exames laboratoriais na quarta semana da doença: uréia $=80 \mathrm{mg} \%$, creatinina $=3,5 \mathrm{mg} \%$, clearance de creatinina $=12 \mathrm{ml} / \mathrm{min} / 1,73 \mathrm{~m}^{2} \mathrm{SC}$, Aslo $=974 \mathrm{Ul} / \mathrm{ml}(\mathrm{N}=$ até 125$)$, $\mathrm{C}_{3}=48,4 \mathrm{mg} \%(\mathrm{~N}=88$ a 201$)$.

Foi orientado a retornar ao ambulatório semanalmente. Duas semanas após a alta, mantinha diurese de 900 a $1000 \mathrm{ml}$, com uréia $=50 \mathrm{mg} \%$, creatinina $=2,1 \mathrm{mg} \%$, sem diálise, porém com as medicações anti-hipertensivas.

\section{CASO 2}

C. P. B., sexo feminino, branca, 66 anos, viúva, procedente de Botucatu (SP). A paciente deu entrada no Hospital das Clínicas da Faculdade de Medicina de Botucatu da Universidade Estadual Paulista (FMB/Unesp), referindo quadro de fraqueza, anorexia, indisposição associada à diminuição da diurese, urina escura e tosse com expectoração espumosa. Apresentava antecedente de infecção de orofaringe há um mês, tratada com tetraciclina.

Ao exame físico, apresentava-se em bom estado geral, afebril, peso $=63 \mathrm{~kg}$, altura $=147 \mathrm{~cm}, P A=140 \times 80 \mathrm{mmHg}$, $\mathrm{FC}=80 \mathrm{bat} / \mathrm{min}, \mathrm{FR}=20 \mathrm{mov} / \mathrm{min}$, estase jugular discreta, roncos em bases pulmonares e fígado palpável a $5 \mathrm{~cm}$ do rebordo costal direito.

Exames laboratoriais de entrada: hemograma: $\mathrm{Ht}=40,2 \%, \mathrm{Hb}=13,5 \mathrm{~g} \%$, glóbulos brancos $=15.600 /$ $\mathrm{mm}^{3}$ com $3 \%$ de bastão, $86 \%$ de segmentados, $10 \%$ de linfócitos e $1 \%$ de monócitos, plaquetas $=202.000 /$ $\mathrm{mm}^{3}$. Exame de urina: densidade $=1025, \mathrm{pH}=5$, proteínas $=4+$, glicosúria $=$ negativa, sangue oculto $=3+$, hemoglobinúria $=3+$ e numerosos leucócitos, hemácias e cilindros granulosos à sedimentoscopia. Urinocultura: negativa. Proteinúria de 12 horas $=860 \mathrm{mg}$. Bioquímicos: proteínas totais $=6,4 \mathrm{~g} \%$, albumina $=3,6 \mathrm{~g} \%$, globulinas $=2,8 \mathrm{~g} \%$, glicemia $=156 \mathrm{mg} \%, \mathrm{Na}=136 \mathrm{mEq} / \mathrm{l}, \mathrm{K}=4 \mathrm{mEq} / \mathrm{l}$,
$\mathrm{Ca}=10 \mathrm{mg} \%, \mathrm{P}=8,2 \mathrm{mg} \%$, ácido úrico $=10,6 \mathrm{mg} \%$, uréia $=174 \mathrm{mg} \%$, creatinina $=1,84 \mathrm{mg} \%$, mucoproteínas $=17,6 \mathrm{mg} \%$, proteína $\mathrm{C}$ reativa $=100 \mathrm{mg} \%, C_{3}=8,3 \mathrm{mg} \%$, $\mathrm{C}_{4}=42,9 \mathrm{mg} \%, \mathrm{FAN}=$ negativo, Anca $=$ negativo. Ultrasom renal $=$ normal, $E C G=$ ritmo sinusal.

Houve piora gradativa da função renal, sendo que 20 dias após a entrada apresentava uréia $=223 \mathrm{mg} \%$, creatinina $=8,3 \mathrm{mg} \%$, clearance de creatinina $=5,34 \mathrm{ml} / \mathrm{min}$ e proteinúria de 24 horas $=3,9 \mathrm{~g}$. Foi submetida à biópsia renal que mostrou glomerulonefrite proliferativa difusa endocapilar exsudativa com $25 \%$ de crescentes associada à necrose tubular aguda. A imunoflorescência demonstrou depósitos granulares difusos de $\mathrm{C}_{3}$ em alças capilares e mesângio. ’̀ microscopia eletrônica observamos depósitos volumosos mesangiais e subepiteliais. O conjunto dos achados foi compatível com glomerulonefrite difusa aguda pós-infecciosa.

Recebeu tratamento de suporte com melhora progressiva da função renal, tendo alta seis dias após a biópsia, com uréia $=122 \mathrm{mg} \%$, creatinina $=2,85 \mathrm{mg} \%$, clearance de creatinina $=14 \mathrm{ml} / \mathrm{min}$.

Cerca de duas semanas após retorna com fraqueza, queda do volume urinário, dispnéia, proteinúria de 24 horas $=9,2 \mathrm{~g}$, uréia $=100 \mathrm{mg} \%$, creatinina $=3,17 \mathrm{mg} \%$, e clearance de creatinina $=9 \mathrm{ml} / \mathrm{min}$. Uma segunda biópsia renal mostrou acentuada piora em relação à biópsia anterior com $80 \%$ de crescentes e $42 \%$ de esclerose glomerular. Observou-se ainda necrose fibrinóide de arteríolas e pequenas artérias com depósitos de $\mathrm{C} 1 \mathrm{q}, \mathrm{C}_{3}$, IgG e fibrina.

A paciente evoluiu rapidamente para insuficiência renal crônica terminal, iniciando diálise cerca de três semanas após. Evoluiu com vários episódios de peritonites e aproximadamente nove meses após apresentou erisipela bolhosa em membro inferior direito e choque séptico, evoluindo para óbito.

\section{Discussão}

A glomerulonefrite difusa aguda pós-infecciosa geralmente se manifesta, em crianças, com quadro agudo de edema, hematúria e hipertensão. Insuficiência renal é incomum e está relacionada a complicações como aparecimento de crescentes ${ }^{(2,4)}$ ou necrose tubular aguda ${ }^{(6)}$. Vasculite necrosante raramente tem sido relatada ${ }^{(1-4,7)}$.

Apresentamos dois pacientes; uma criança e um adulto com quadro nefrítico agudo e insuficiência renal rapidamente progressiva. Inicialmente, os dados clínicos sugeriram glomerulonefrite crônica progressiva associada a doença sistêmica. No entanto, o aparecimento agudo dos 
sintomas com complemento baixo favorece o diagnóstico de glomerulonefrite difusa aguda pós-infecciosa. Um dos pacientes apresentou história de infecção prévia de orofaringe que foi tratada, havendo também um período de latência entre a infecção e o aparecimento da glomerulonefrite. Na criança não foi detectada infecção prévia, porém apresentou febre e altos títulos de Aslo. Morfologicamente, as lesões glomerulares caracterizaram-se por proliferação difusa mesangioendotelial com acentuado exsudato de neutrófilos, padrão comumente descrito na GNDA. Por outro lado, a pesquisa positiva de imunocomplexos em glomérulos e vasos, pela imunofluorescência e ultra-estrutura foi fundamental para a confirmação da hipótese clínica de GNDA pós-infecciosa.

Interpretamos as lesões glomerulares e vasculares como fazendo parte de um mesmo processo imunopatológico. Vasculite necrosante dos pequenos vasos mediada por imunocomplexos pode ser induzida por infecção bacteriana e estar associada a GNDA ${ }^{(2,7)}$. Foram descritos na literatura 13 casos semelhantes, oito crianças e cinco adultos jovens com infecção estreptocócica, que desenvolveram GNDA associada à necrose fibrinóide de pequenas artérias ${ }^{(1-4,7)}$.

Embora raramente, glomerulonefrite proliferativa e vasculite podem também fazer parte das manifestações sistêmicas da febre reumática ${ }^{(6,10)}$. Têm sido descritos ainda casos de
GNDA com lesões purpúricas na pele e hemorragia gastrointestinal, sendo consideradas variantes da GNDA pós-estreptocócica mimetizando a púrpura de Henoch-Schönlein ${ }^{(5)}$.

As vasculites sistêmicas, além de se associarem ao Anca, mostram lesões glomerulares com predomínio de necrose e não-proliferação celular, e com pesquisa negativa para imunodepósitos ${ }^{(8,9)}$. Fordham et al. ${ }^{(4)}$ ao descreverem quatro casos de adultos jovens com GNDA pós-estreptocócica e vasculite necrosante generalizada, denominaram as lesões vasculares de poliarteríticas. Porém, concluem tratar-se de casos de síndrome pós-estreptocócica caracterizada por GNDA apresentando vasculite necrosante.

Ambos os casos desenvolveram, durante a evolução, necrose tubular aguda, e elevada porcentagem de crescentes que, associadas à lesão vasculítica, determinaram queda rápida da função renal. Dos 13 casos descritos na literatura, oito apresentaram proliferação extracapilar ${ }^{(1-4)}$. No entanto, todas as crianças evoluíram com recuperação da função renal, mesmo as que apresentaram número elevado de crescentes $^{(2,3)}$. Dos cinco adultos relatados, quatro evoluíram para óbito e um apresentou remissão da doença $a^{(1,4)}$.

Em conclusão, a vasculite necrosante descrita é uma lesão por imunocomplexos conseqüente ao processo infeccioso, mais do que uma poliarterite idiopática coincidente com a lesão glomerular.

\section{Referências}

I. ANDRES, G. A. et al. Electron microscopic studies of human glomerulonephritis with ferritin-conjugated antibody. J Exp Med, v. 123, p. 399-4I2, 1966.

2. BODAGHI, E.; KHERADPIR K. M. H.; MADDAH, M. Vasculitis in acute streptococcal glomerulonephritis. Intern.J Ped Nephrol, v. 8, n. 2, p. 69-74, 1987

3. Case records of the Massachussets General Hospital (case 6-1975). N Eng J Med, v. 292, p. 307-12, 1975.

4. FORDHAM, C. C. et al. Polyarteritis and acute post-streptococcal glomerulonephritis. Ann Intern Med, v. 6I, p. 89-97, 1964.

5. GOODYER, P. R.; de CHADAREVIAN, J. P.; KAPLAN, B. S Acute poststreptococcal glomerulonephritis mimicking Henoch-Schönlein purpura. J Pediatr, v. 93, n. 3, p. 4I2-5, 1978.

6. GUTIÉRREZ UREÑA, S. et al. Poststreptococcal reactive arthritis, clinical course, and outcome in adults patients.J Rheumatol, v. 22, n. 9, p. $1710-3,1995$.

7. INGELFINGER, J. R. et al. Necrotizing arteritis in acute poststreptococcal glomerulonephritis. J Pediatr, v. 91, n. 2, p. 228-32, 1977
8. JENNETTE, J. C. et al. Nomenclature of systemic vasculitides. Proposal of an International Consensus Conference. Arthritis and Rheum, v. 37, n. 2, p. 187-92, 1994

9. JENNETTE, J. C.; FALK, R. J. Current concepts in renal pathology: the pathology of vasculitis involving the kidney. Am J Kidney Dis, v. 24, n. I, p. I30-4I, 1994.

I0. LIVNEH, A. et al. Multisystem disease in post-streptococcal arthritis. Ann Rheum Dis, v. 50, p. 328-9, 1991.

I I. SOARES, V. A. et al. Necrose tubular aguda associada a glomerulonefrite difusa aguda. Estudo retrospectivo anatomoclínico de cinco casos. J Bras Nefrol, v. 5, n. 2, p. 39-42, 1983.

\begin{tabular}{l|l} 
& \\
& Endereço para correspondência \\
\hline & Rosa M. Viero \\
Departamento de Patologia da \\
Faculdade de Medicina de Botucatu/Unesp \\
CEP 18618-000 - Botucatu-SP \\
Tel.: (14) 6802-6238 \\
Fax: (14) 6821-2348 \\
E-mail: viero@fmb.unesp.br
\end{tabular}

